\title{
Evaluation of prognostic scores for respiratory syncytial virus infection in a French multicentre cohort of allogeneic haematopoietic stem cell transplantation recipients
}

Anne-Laure Houist ${ }^{1}$, Louise Bondeelle ${ }^{2}$, Maud Salmona ${ }^{3}$, Jérôme LeGoff ${ }^{3}$, Régis Peffault de Latour ${ }^{4}$, Frédéric Rivière iD $^{5}$, Charles Soler ${ }^{6}$ Véronique Houdouin ${ }^{7}$, Jean-Hugues Dalle ${ }^{8}$, Christine Robin (iD ${ }^{9}$, Slim Fourati ${ }^{10}$, Franck Griscelli $^{11}$, Tereza Coman $^{12}$, Sylvie Chevret ${ }^{13,14}$ and Anne Bergeron (iD ${ }^{2,14 凶}$

(c) The Author(s), under exclusive licence to Springer Nature Limited 2021

Haematopoietic stem cell transplantation (HSCT) recipients are at risk for severe respiratory syncytial virus (RSV) infection. Two prognostic scores have been proposed to predict the risk of progression from upper respiratory tract infection (URTI) to lower respiratory tract infection (LRTI) and death. This was a multicentre study of allogeneic HSCT recipients diagnosed with an RSV infection between 2010 and 2019 who were retrospectively stratified by the immunodeficiency scoring index (ISI) and the severe immunodeficiency (SID) score. Endpoints were overall survival, RSV-attributable mortality and progression to LRTI after URTI. Prognostic analyses were performed using Cox regression models. We included 147 consecutive patients, including 94 (63.9\%) initially diagnosed with URTI and 53 (36.1\%) with LRTI. At 90 days, 14 patients had died (survival rate, 90.5\%; 95\% Cl: 85.9-95.3), and nine deaths were attributable to RSV (attributable mortality rate, 5.4\%; $95 \%$ Cl: $2.5-10.0$ ). The cumulative 90 -day incidence of LRTI after URTI was $13.8 \%$ (95\% Cl: 7.8-21.6). Neither score showed prognostic value for mortality, while the ISI allowed the prediction of progression to LRTI $(p=0.0008$ ). Our results do not fully replicate the results previously reported in cohorts of HSCT recipients. This may reflect the recent epidemiology of RSV infections in this HSCT cohort.

Bone Marrow Transplantation (2021) 56:3032-3041; https://doi.org/10.1038/s41409-021-01462-z

\section{INTRODUCTION}

In the course of allogeneic haematopoietic stem cell transplantation (HSCT), respiratory syncytial virus (RSV) infection can lead to severe infection with a poor prognosis [1-5]. RSV infection is seasonal, with recurrent winter outbreaks with various annual incidences ranging from 2 to $49 \%[6,7]$ in allogeneic HSCT recipients. Upper respiratory tract infection (URTI) is usually minor, but the risk of progression to lower respiratory tract infection (LRTI) is high, especially in the early phase of HSCT, and it has been associated with mortality [7-10].

Although the widespread use of molecular diagnostics allows earlier diagnosis and HSCT postponement in the case of a pretransplant RSV-positive test [11], the mortality rate attributable to RSV remains significant, being approximately $10 \%$ in adults $[9,12]$ and $<5 \%$ in children [13] in recent studies. The identification of risk factors for progression to LRTI and death in allogeneic HSCT patients has been the subject of several publications [4, 14, 15], with the aim of defining the population of patients who would benefit from antiviral treatment.
Two severity scores have been developed to classify patients according to the risk for progression to LRTI and the risk of RSVattributable mortality [11, 16]. The "Immunodeficiency Scoring Index" (ISI) from the MD Anderson Cancer Center was established in 2014 [16, 17], and the "Severe Immuno-Deficiency" (SID) score was proposed by a single-institutional study from the University of Basel in 2008 [11]. These two grading systems aim to classify patients into 3 risk categories (low, moderate and high for the ISI and moderate, severe, and very severe for the SID score), relying on both clinical and biological criteria (Supplementary Table 1).

Current treatments for RSV are limited, but the guidelines of the 8th European Conference on Infections in Leukaemia [18] recommend systemic or aerosolized ribavirin, a broad-spectrum molecule used against many RNA viruses, with or without the associated use of intravenous polyclonal immunoglobulins (IVIGs) in both cases of LRTI and URTI with a high risk of progression to LRTI. Indeed, the pooling of cohort studies assessing the efficacy of ribavirin has suggested a reduction in both LRTI progression and mortality $[6,17,19-22]$. However, meta-analyses have

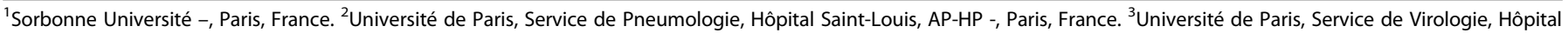

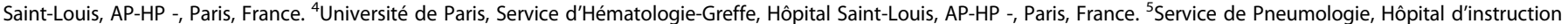

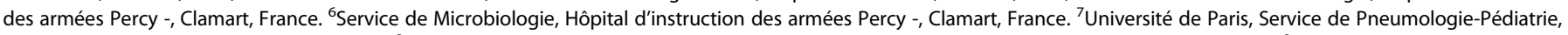

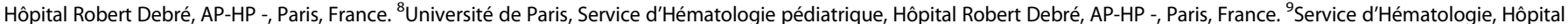

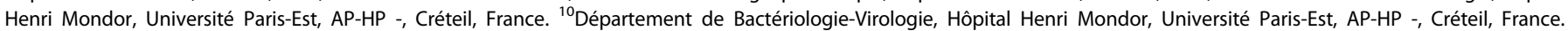

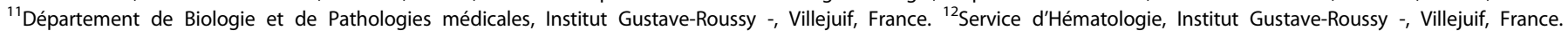

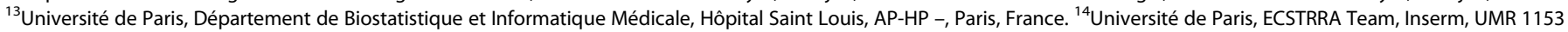
CRESS, F-75010 Paris, France. ${ }^{\bowtie}$ email: anne.bergeron@hcuge.ch
} 
included studies that are difficult to compare, especially studies involving different RSV diagnostic techniques and heterogeneous management strategies [11]. Only one randomized controlled study was conducted to investigate the efficacy of aerosolized ribavirin, but difficulty in enrolling patients led to early termination; it was, therefore, impossible to draw a firm conclusion [23].

Other molecules are being developed, in particular presatovir, an RSV fusion inhibitor. A randomized placebo-controlled study failed to demonstrate a significant antiviral effect and a reduction in LRTI progression in HSCT patients with RSV-URTI, although post hoc analysis found an effect specifically in patients with lymphopenia [24]. Similarly, presatovir did not improve virologic or clinical outcomes compared with placebo in HSCT patients with RSV-LRTI [25]. At a time when new molecules are being evaluated, similar future trials should judiciously select suitable at-risk patients to maximize the potential benefits. Because LRTI increases the risk of mortality, the prompt diagnosis of and early intervention for RSV-URTI in high-risk patients with effective antiviral agents are imperative to improve the clinical outcomes.

The aim of our study was to assess the prognostic value of both the ISI and the SID score using a recent multicentre cohort of allogeneic HSCT recipients.

\section{MATERIALS AND METHOD Study design}

Both paediatric and adult allogeneic HSCT patients diagnosed with RSV infection by polymerase chain reaction (PCR) at the following five French hospitals were retrospectively included in the study: Saint Louis Hospital (Paris), Robert Debré Hospital (Paris), Gustave Roussy Institute (Villejuif), Percy Hospital (Clamart), and Henri Mondor Hospital (Créteil). All RSV-positive respiratory samples collected in the virology laboratory of each site were screened from the date of implementation of PCR (depending on each site) until December 2019. PCR for RSV was being used routinely first at Saint Louis Hospital and Robert Debré Hospital in December 2010 and January 2011, respectively; Percy Hospital, Henri Mondor Hospital, and Gustave Roussy Institute have been using it since December 2011, January 2015, and January 2016, respectively. Clinical data were collected from patient's medical charts. All chest imaging data were reviewed (ALH, LB, AB). Patients were included if PCR for RSV yielded a positive result from 10 days prior to HSCT to any time after transplantation. This study was approved by the Institutional Review Board of the French Learned Society for Respiratory Medicine, Société de Pneumologie de Langue Française (CEPRO 2019-040), and the data collected was anonymized prior to processing (Redcap software).

\section{Outcomes and definitions}

The primary endpoint was overall survival (OS). Secondary endpoints were early mortality (any death within 90 days after RSV infection), RSV-attributable mortality, and, for patients with URTI, progression to LRTI.

The diagnosis of URTI was defined by detection of the virus in the upper respiratory tract with symptoms of URTI (rhinitis, pharyngitis, laryngitis, conjunctivitis, sinusitis) without hypoxemia or infiltration on chest imaging.

RSV infections were classified according to the ECIL8 definitions [18]. Briefly, the diagnosis of LRTI was defined by the association of respiratory symptoms with (i) pulmonary infiltration on chest imaging (within five days before and after infection diagnosis) or hypoxemia and (ii) the identification of RSV in the upper or lower respiratory tract. LRTI was classified as "probable" or "presumptive" LRTI when the virus was detected in the upper airway (i.e. by nasal swab, nasopharyngeal lavage, or nasopharyngeal aspiration) or in the lower respiratory tract (i.e. by endotracheal aspiration or bronchoalveolar lavage), respectively.
Progression of URTI to LRTI was defined by new-onset lung infiltration on radiology, hypoxemia, or lower respiratory tract virus detection in a patient who initially presented with URTI. Coinfection was defined by the identification of another pathogen (bacterial, viral, or fungal) within 3 days before or after a positive RSV-PCR result. Data regarding coinfection at the time of progression to LRTI were also collected.

An episode was considered multiple episodes when there was a four-week time interval between two positive PCR results for RSV or a negative PCR result between two episodes. Nosocomial RSV was defined by the occurrence of RSV infection at least $72 \mathrm{~h}$ after the patient's hospital admission, provided that signs and symptoms related to the infection were not present at the time of admission.

Lymphoproliferative diseases included lymphoma, chronic lymphoid leukaemia, and myeloma.

All-cause mortality was defined as any death within the 90 days following the diagnosis of RSV infection. RSV-attributable mortality was defined as death due to respiratory failure with no cause other than identified RSV. Acute or chronic graft-versus-host disease (GVHD) was evaluated at the time of RSV diagnosis [26].

\section{ISI and SID score}

All patients were classified according to the criteria of both the ISI and the SID score at the time of RSV diagnosis (Supplementary Table 1). The ISI ranged from 0 to 12 , calculated as follows $[16,17]$ : three points for either neutropenia $\leq 0.5 \times 10^{9} / \mathrm{l}$ or lymphopenia $\leq 0.2 \times 10^{9} /$; two points for age $\geq 40$ years; and one point each for myeloablative conditioning regimen, GVHD, corticosteroid therapy within 30 days before RSV infection, recent HSCT (less than 1 month prior) or no engraftment. Allogeneic HSCT recipients were then stratified into risk levels for severe RSV infection: low risk (ISI, 0-2); moderate risk (ISI, 3-6); and high risk (ISI, 7-12). The SID score was also used to classify patients into three categories: moderate immunodeficiency (MID); severe immunodeficiency (SID); and very severe immunodeficiency (verySID). MID was defined as follows: HSCT $>6$ months prior; B or T lymphocyte depletion $>3$ months; neutropenia $>0.5 \times 10^{9} / \mathrm{l}$ and lymphocyte count $>0.1 \times 10^{9} /$; GVHD $<$ grade 2 or untreated; and hypogammaglobulinemia $>6.5 \mathrm{~g} / \mathrm{L}$. In contrast, SID was defined by one and verySID was defined by two or more of the following risk factors: $\mathrm{HSCT} \leq 6$ months prior; B or T lymphocyte depletion $\leq 3$ months; neutropenia $\leq 0.5 \times 10^{9} /$; lymphopenia $\leq 0.1 \times 10^{9} /$; GVHD grade $\geq 2$ or treated; and hypogammaglobulinemia $\leq 6.5 \mathrm{~g} / \mathrm{L}[11,27]$.

\section{Statistical analysis}

Descriptive statistics, namely, the median with the interquartile range (IQR), or percentages are reported. Only the first episode of infection was considered for survival analyses, starting from the date of diagnosis to the date of death or the last follow-up. The OS distribution was estimated by the Kaplan-Meier method, while mortality attributable to RSV was estimated by cumulative incidence curves in a competing-risks setting where death from other causes was defined as a competing risk event. For the cumulative incidence of LRTI, only subjects with URTI were considered, with the death without progression defined as a competing risk outcome. Prediction models were cause-specific Cox models, with the cause-specific hazard ratio (HR) as the measure of the effect reported with the $95 \%$ confidence interval $(\mathrm{Cl})$. Univariable models were fitted, and multivariable models were used, including factors associated with the outcome at the $10 \%$ level. A stepwise selection procedure was used based on the Akaike criterion. Log-linear relationships were checked using generalized additive models with splines, while proportional hazards assumptions were checked by the Grambsch and Therneau statistical test [28]. Last, we reran the analyses specifically on the adult patients (age $\geq 18 \mathrm{yrs}$ ), given the SID 
Table 1. Baseline characteristics at the first episode of RSV infection.

\begin{tabular}{|c|c|c|c|}
\hline Characteristics, n (\%) & $\begin{array}{l}\text { Total } \\
(n=147)\end{array}$ & $\begin{array}{l}\text { LRTI } \\
(n=53)\end{array}$ & $\begin{array}{l}\text { URTI } \\
(n=94)\end{array}$ \\
\hline $\begin{array}{l}\text { Age at allogeneic HSCT, } \\
\text { year, median [IQR] }\end{array}$ & $\begin{array}{l}40.2 \\
{[22.0 ; 56.6]}\end{array}$ & $\begin{array}{l}49.2 \\
{[32.7 ; 57.8]}\end{array}$ & $\begin{array}{l}36.22 \\
{[19.4 ; 54.5]}\end{array}$ \\
\hline Male & $91(61.9)$ & $33(62.3)$ & $58(61.7)$ \\
\hline \multicolumn{4}{|l|}{ Haematological disease } \\
\hline $\begin{array}{l}\text { Haematological } \\
\text { malignancy }\end{array}$ & $131(89.1)$ & $49(92.5)$ & $82(87.2)$ \\
\hline Non-malignancy & $16(10.9)$ & $4(7.5)$ & $12(12.8)$ \\
\hline \multicolumn{4}{|l|}{ Underlying disease } \\
\hline Acute leukaemia & $65(44.2)$ & $26(49.1)$ & $39(41.5)$ \\
\hline CLL & $1(0.7)$ & 0 & $1(1.1)$ \\
\hline CML & $5(3.4)$ & $3(5.7)$ & $2(2.1)$ \\
\hline Lymphoma & $22(14.9)$ & $10(18.9)$ & $12(12.8)$ \\
\hline Myeloma & $12(8.1)$ & $5(9.4)$ & $7(7.4)$ \\
\hline $\begin{array}{l}\text { Myelodysplastic } \\
\text { syndrome }\end{array}$ & $10(6.8)$ & $1(1.9)$ & $9(9.6)$ \\
\hline $\begin{array}{l}\text { Myeloproliferative } \\
\text { syndrome }\end{array}$ & $1(0.7)$ & 0 & $1(1.1)$ \\
\hline Myelofibrosis & $10(6.8)$ & $2(3.8)$ & $8(8.5)$ \\
\hline Sickle cell disease & $9(6.1)$ & $2(3.8)$ & $7(7.4)$ \\
\hline Medullary aplasia & $7(4.7)$ & $2(3.8)$ & $5(5.3)$ \\
\hline Other & $5(3.4)$ & $1(1.9)$ & $4(4.2)$ \\
\hline \multicolumn{4}{|l|}{ Donor } \\
\hline Related & $72(49)$ & $28(52.8)$ & $44(46.8)$ \\
\hline Unrelated $^{\mathrm{a}}$ & $75(51)$ & $25(47.2)$ & $50(53.2)$ \\
\hline \multicolumn{4}{|l|}{ Stem cell source } \\
\hline $\begin{array}{l}\text { Peripherical } \\
\text { stem cells }\end{array}$ & $116(78.9)$ & $46(86.8)$ & $70(74.5)$ \\
\hline Bone marrow & $15(10.2)$ & $2(3.8)$ & $13(13.8)$ \\
\hline Cord blood & $16(10.9)$ & $5(9.4)$ & $11(11.7)$ \\
\hline \multicolumn{4}{|l|}{ Conditioning regimen } \\
\hline Myeloablative & $59(40)$ & $20(37.7)$ & $39(41.5)$ \\
\hline $\begin{array}{l}\text { Antithymocyte } \\
\text { globulin }\end{array}$ & $73(49.7)$ & $23(43.4)$ & $50(53.2)$ \\
\hline $\begin{array}{l}\text { Whole-body } \\
\text { irradiation }\end{array}$ & $61(41.5)$ & $25(47.2)$ & $36(38.3)$ \\
\hline \multicolumn{4}{|c|}{ Haematological status at RSV infection } \\
\hline Complete remission & $109(74.2)$ & $40(75.5)$ & $69(73.4)$ \\
\hline Relapse & $12(8.2)$ & $4(7.6)$ & $8(8.5)$ \\
\hline Partial remission & $8(5.4)$ & $5(9.4)$ & $3(3.2)$ \\
\hline \multicolumn{4}{|l|}{ GVHD } \\
\hline Acute GVHD & $31(21.1)$ & $14(26.4)$ & $17(18.1)$ \\
\hline Grade $>2$ or treated & $30(81.1)$ & $13(92.9)$ & $17(73.9)$ \\
\hline Chronic GVHD & $56(38.1)$ & $24(45.3)$ & $32(34.1)$ \\
\hline Moderate/severe & $49(79)$ & $17(70.8)$ & $32(84.2)$ \\
\hline $\begin{array}{l}\text { Bronchiolitis obliterans } \\
\text { syndrome }\end{array}$ & $19(12.9)$ & $11(20.8)$ & $8(8.5)$ \\
\hline $\begin{array}{l}\text { Immunosuppressive } \\
\text { treatment }\end{array}$ & $122(82.9)$ & $42(79.3)$ & $80(85.1)$ \\
\hline Calcineurin inhibitor $^{\mathrm{b}}$ & $90(73.8)$ & $27(64.3)$ & $63(78.8)$ \\
\hline $\begin{array}{l}\text { Mycophenolate } \\
\text { mofetil }\end{array}$ & $27(22.1)$ & $10(23.8)$ & $17(21.3)$ \\
\hline Methotrexate & $11(9)$ & $3(7.1)$ & $8(10)$ \\
\hline Others & $11(9)$ & $4(9.5)$ & $7(8.8)$ \\
\hline
\end{tabular}

Table 1 continued

\begin{tabular}{|c|c|c|c|}
\hline Characteristics, $n$ (\%) & $\begin{array}{l}\text { Total } \\
(n=147)\end{array}$ & $\begin{array}{l}\text { LRTI } \\
(n=53)\end{array}$ & $\begin{array}{l}\text { URTI } \\
(n=94)\end{array}$ \\
\hline $\begin{array}{l}\text { Corticosteroid therapy } \\
\text { in the prior } 30 \text { days }\end{array}$ & $71(48.3)$ & $26(49.1)$ & $45(47.9)$ \\
\hline B cell depletion ${ }^{c}$ & $14(9.5)$ & $6(11.3)$ & $8(8.51)$ \\
\hline
\end{tabular}

$R S V$ respiratory syncytial virus, $L R T I$ lower respiratory tract infection, URTI upper respiratory tract infection, HSCT haematological stem cell transplantation, IQR interquartile range, CLL chronic lymphoid leukaemia, CML chronic myeloid leukaemia, GVHD graft-versus-host disease, IVIG intravenous polyclonal immunoglobulins.

${ }^{\mathrm{a}}$ Ten out of 10 and nine out of 10 allelic unrelated donors and cord blood transplants, respectively.

${ }^{\mathrm{b}}$ Cyclosporine, tacrolimus.

cAll patients received rituximab (10 patients within the three months prior to RSV infection and four patients between four months and six months prior to RSV infection).

score has been only developed on such a population [11] while the cohort used for the ISI also included children [16, 17].

All the analyses were carried out in R 3.6.2 (http://www.Rproject.org).

\section{RESULTS}

Patients

Over a nine-year period, 251 samples from allogeneic HSCT patients tested positive for RSV by PCR, including samples from 147 patients who developed a total of 154 RSV episodes: 140 patients developed one episode, and 7 patients developed 2 episodes. The study population included adults and children (age $<18, n=29$ ), with a median age at the time of HSCT of 40.2 years (IQR: 22-56.6). Baseline characteristics are summarized in Table 1. Of these 147 patients, 94 (63.9\%) presented with URTI and 53 with LRTI (36.1\%) at the time of diagnosis with RSV infection. There were $11(7.5 \%)$ cases of nosocomial infection (4 LRTI and 7 URTI cases). The characteristics of the first episode of RSV infection are shown in Table 2.

\section{Outcomes}

The median follow-up was 23 months (IQR: 9.1-36.6). A total of 53 deaths occurred, including 14 within the first 90 days after RSV diagnosis, with an estimated 90-day survival of $90.5 \%(95 \% \mathrm{Cl}$ : 85.9-95.3\%) (Fig. 1). Nine deaths were attributable to RSV, all of which occurred within the first 90 days. The cumulative RSVattributable mortality rate at 90 days was $5.4 \%$ (95\% Cl: $2.5-10.0)$ (Fig. 2). There was no significant difference in survival between LRTI and URTI (Fig. 1). The stratification of disease severity according to either the ISI or SID score did not demonstrate any difference in either overall mortality or RSV-attributable mortality both for the entire cohort and those restricted to the adults (Fig. 1; supplementary Figure 2; Supplementary Fig. 3).

The results of the prognostic analyses are reported in Table 3. In the univariate analyses of 90-day survival, the factors selected at the $5 \%$ level were the same, with the addition of hypogammaglobulinemia ( $\mathrm{HR}=3.91 ; 95 \% \mathrm{Cl}: 1.09-14.01 ; p=0.036)$. In the multivariable analysis, only age was added to the other prognostic information, encompassing the whole follow-up period (Table 3, Supplementary Fig. 1). When restricting on adult patients, only leukocytes count below $2 \mathrm{Giga} / \mathrm{L}(\mathrm{HR}=2.56 ; 95 \% \mathrm{Cl}$ : $1.20-5.56 ; p=0.015$ ), and use of corticosteroids within 30 days of RSV infection $(\mathrm{HR}=2.16 ; 95 \% \mathrm{Cl}: 1.22-3.84 ; p=0.009)$ were associated with the outcome.

\section{Progression to LRTI}

Of the 94 patients with URTI, 13 progressed to LRTI, with a cumulative incidence of progression of $13.8 \%$ at 90 days $(95 \% \mathrm{Cl}$ : 
Table 2. Characteristics of RSV infection.

\begin{tabular}{|c|c|c|c|}
\hline Characteristics & Total $(n=147)$ & LRTI $(n=53)$ & URTI $(n=94)$ \\
\hline Median delay from allogeneic HSCT to RSV infection (days, IQR) & $\begin{array}{l}196 \\
{[86 ; 411.5]}\end{array}$ & $\begin{array}{l}272 \\
{[105 ; 608]}\end{array}$ & $\begin{array}{l}174.5 \\
{[74.5 ; 345]}\end{array}$ \\
\hline \multicolumn{4}{|l|}{ PCR sample } \\
\hline Nasopharyngeal aspiration & $64(43.5)$ & $20(37.7)$ & $44(46.8)$ \\
\hline Bronchoalveolar lavage & $3(2)$ & $3(5.7)$ & 0 \\
\hline Bacterial coinfection & $23(15.7)$ & $22(41.5)$ & $1(1.1)$ \\
\hline Fungal coinfection & $3(2.0)$ & $3(5.7)$ & 0 \\
\hline \multicolumn{4}{|l|}{ Biology } \\
\hline $\mathrm{ALC} \leq 0.5 \times 10^{9} / \mathrm{I}$ & $52(35.4)$ & $21(39.6)$ & $31(32.9)$ \\
\hline $\mathrm{ALC} \leq 0.2 \times 10^{9} / \mathrm{I}$ & $21(14.3)$ & $10(18.9)$ & $11(11.7)$ \\
\hline Progression to LRTI & $13(13.8)$ & - & $13(13.8)$ \\
\hline Hospital admission & $63(42.9)$ & $41(77.4)$ & $22(23.4)$ \\
\hline ICU & $7(4.7)$ & $4(7.6)$ & $3(3.2)$ \\
\hline Mechanical ventilation & $4(57.1)$ & $2(50)$ & $2(66.7)$ \\
\hline Overall deaths & $53(36.1)$ & $23(43.4)$ & $30(31.9)$ \\
\hline Deaths at 90 days & $14(9.5)$ & $6(11.3)$ & $8(8.5)$ \\
\hline Deaths attributed to RSV & $9(6.1)$ & $4(7.6)$ & $5(5.3)$ \\
\hline Treatment for RSV ${ }^{b}$ & $45(30.6)$ & $19(35.8)$ & $26(27.7)$ \\
\hline Ribavirin & $15(33.3)$ & $7(36.8)$ & $8(30.8)$ \\
\hline Ribavirin + IVIG & $7(15.6)$ & $4(21.1)$ & $3(11.5)$ \\
\hline Low & $62(42.2)$ & $12(22.6)$ & $50(53.2)$ \\
\hline Moderate & $77(52.4)$ & $38(71.7)$ & $39(41.5)$ \\
\hline High & $8(5.4)$ & $3(5.7)$ & $5(5.3)$ \\
\hline
\end{tabular}

$R S V$ respiratory syncytial virus, $L R T I$ lower respiratory tract infection, URTI upper respiratory tract infection, HSCT haematologic stem cell transplantation, IQR interquartile range, GVHD graft-versus-host disease, $A L C$ absolute lymphocyte count, $A N C$ absolute neutrophil count, SID score severe immunodeficiency score, MID moderate immunodeficiency, SID severe immunodeficiency, ISI immunodeficiency scoring index.

${ }^{a}$ Coinfection, including by viruses (Rhinovirus $n=12$, Coronavirus $n=10$, Enterovirus $n=10$, Influenza virus $n=6$, Parainfluenza virus $n=7$, adenovirus $n=4$, metapneumovirus $n=1$ and bocavirus $n=1$ ), bacteria (Streptococcus pneumonae $n=6$, Klebsiella pneumonae $n=4$, Pseudomonas aeruginosa $n=4$, Branhamella catarrhalis $n=4$, Haemophilus influenzae $n=3$, Escherichia coli $n=1$, others $n=$ ), and fungi (Aspergillus fumigatus $n=3$ ).

${ }^{\mathrm{b}}$ Four patients were included in a randomized trial (presatovir vs placebo).

7.8-21.6) (Fig. 3). The ISI identified three groups of patients with a specific risk for progression to LRTI $(p=0.0008)$. In contrast, the SID score could not predict progression to LRTI ( $p=0.43$ ) (Fig. 3).

The results of the univariable analyses identifying risk factors for progression are reported in Table 4 . In the multivariable model, only a history of $\mathrm{B}$ cell depletion $(\mathrm{HR}=5.7 ; 95 \% \mathrm{Cl}$ : 1.47-22.2) and the ISI (moderate: $\mathrm{HR}=5.9 ; 95 \% \mathrm{Cl}: 1.25-27.7$; high: $\mathrm{HR}=27.5$; $95 \%$ Cl: 4.3-175) remained significantly associated with LRTI. On the subsample of 118 adult patients, only one patient had a high ISI score; similar predictors were selected, namely history of B cells depletion ( $\mathrm{HR}=12.1 ; 95 \% \mathrm{Cl}: 2.20-66.5)$ and the ISI (moderate: HR $=5.23 ; 95 \% \mathrm{Cl}: 1.00-27.3)$, with additional decreased hazard of
LRTI though statistically non-significant for verySID patients ( $H R=$ 0.22; 95\%Cl: 0.04-1.13; $p=0.070$ ) (supplementary Figure 4).

\section{DISCUSSION}

Our results show that the ISI but not the SID score was predictive of progression from RSV-URTI to LRTI in a multicentre retrospective cohort of allogeneic HSCT recipients. However, we found that neither of these scores predicted either overall mortality or RSV-attributable mortality.

RSV-associated mortality was the primary endpoint of previous studies, including overall RSV-associated mortality for the SID 

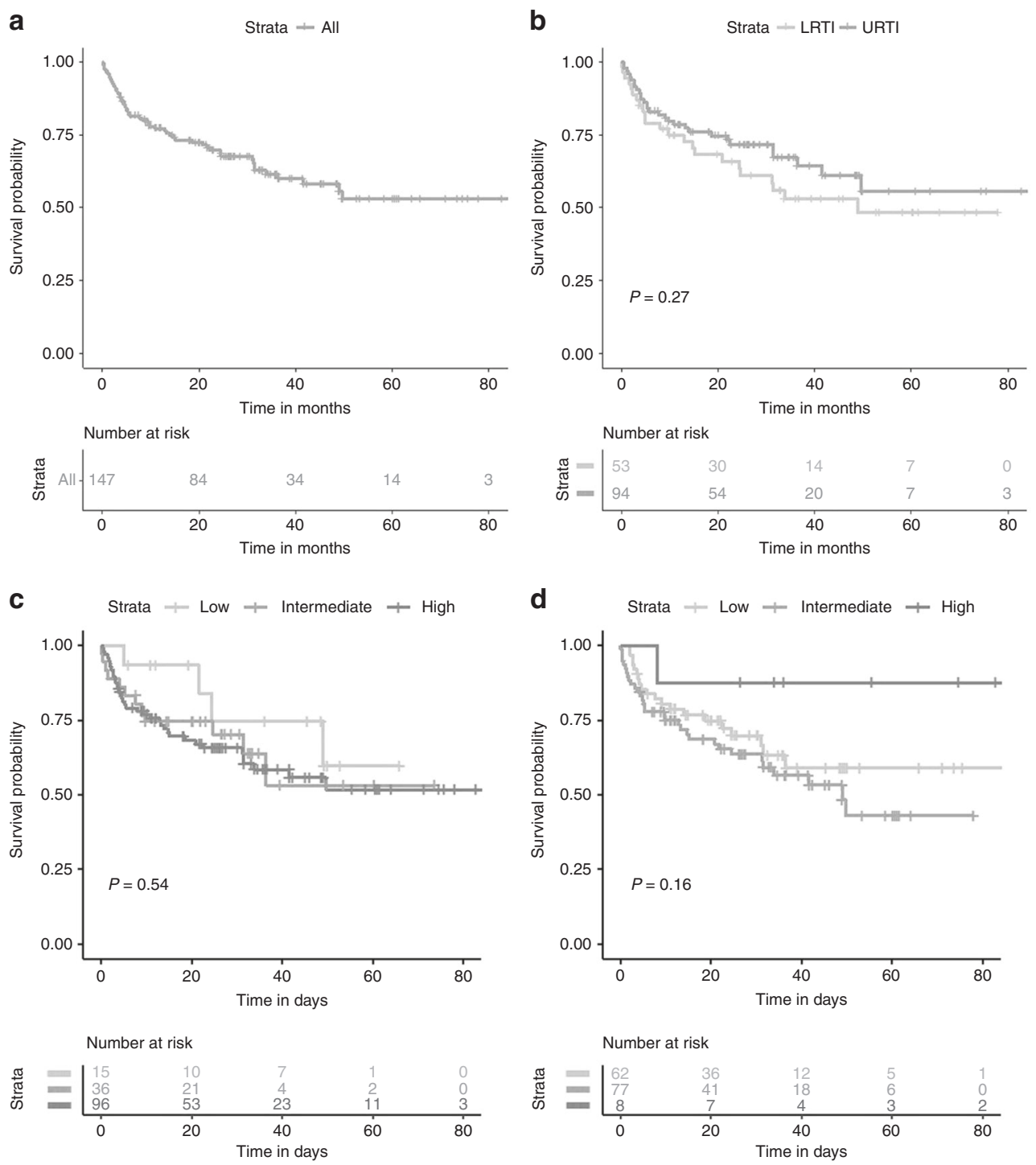

Fig. 1 Kaplan-Meier curves of survival after RSV diagnosis. a Overall survival in the whole population of patients. b overall survival according to the site of infection. c overall survival within 90-days according to the risk groups defined by the Severe ImmunoDeficiency score. d overall survival within 90 -days according to the risk groups defined by Immunodeficiency scoring index.
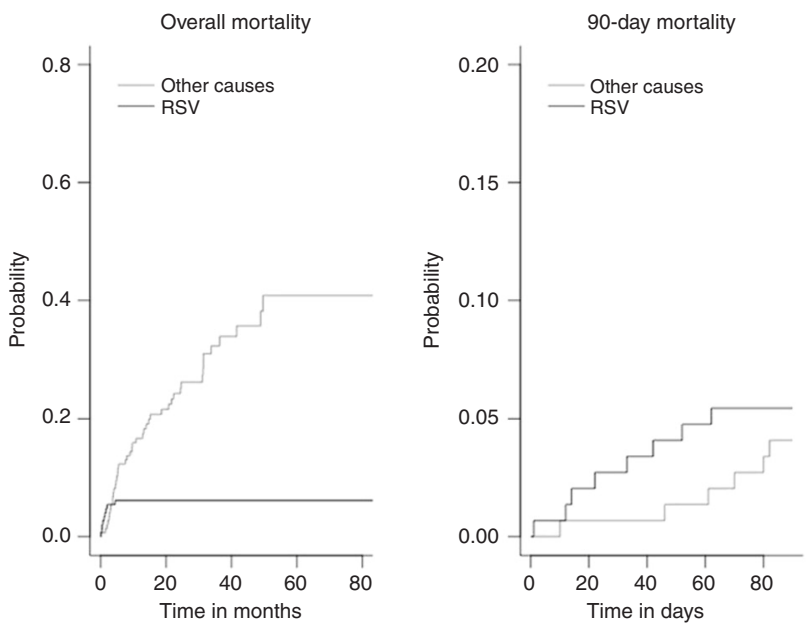

Fig. 2 Cumulative incidence of death according to the cause, either related to RSV or not. Left plots refer to overall mortality, right plots refer to 90 -day mortality.

score and 90-day RSV-associated mortality for the ISI. Because it is usually difficult to establish a single cause of death in allogeneic HSCT patients, in whom mortality is often multifactorial and involves numerous associated complications [21, 29], classification errors are probable in retrospective cohorts. Therefore, as carried out in previous studies $[9,30-32]$, we primarily analysed OS and truncated survival at 90 days as prognostic factors. We subsequently extended the study to include RSV-associated mortality for comparison with previous studies.

Our study highlights the recent epidemiology of RSV infection in allogeneic HSCT patients. We found an overall mortality rate of $9.5 \%$ at 90 days and a cumulative RSV-attributable mortality rate of $5.4 \%$. Furthermore, few patients required transfer to the intensive care unit (ICU). In studies conducted in the 1990s2000s, the RSV-attributable mortality rate was between $30 \%$ and $80 \%[10,33,34]$, whereas more recent studies found an RSVattributable mortality rate of $6-10 \%[9,12,30]$. In the specific cohorts of the ISI and the SID score, the RSV-attributable mortality rate was $8 \%$ and $18 \%$, respectively.

The differences between our cohort and both the SID score and ISI cohorts may explain the lack of full validation of both scores. Both the ISI and the SID score are based on older cohorts of 
Table 3. Univariate and multivariate prognostic analyses for overall survival.

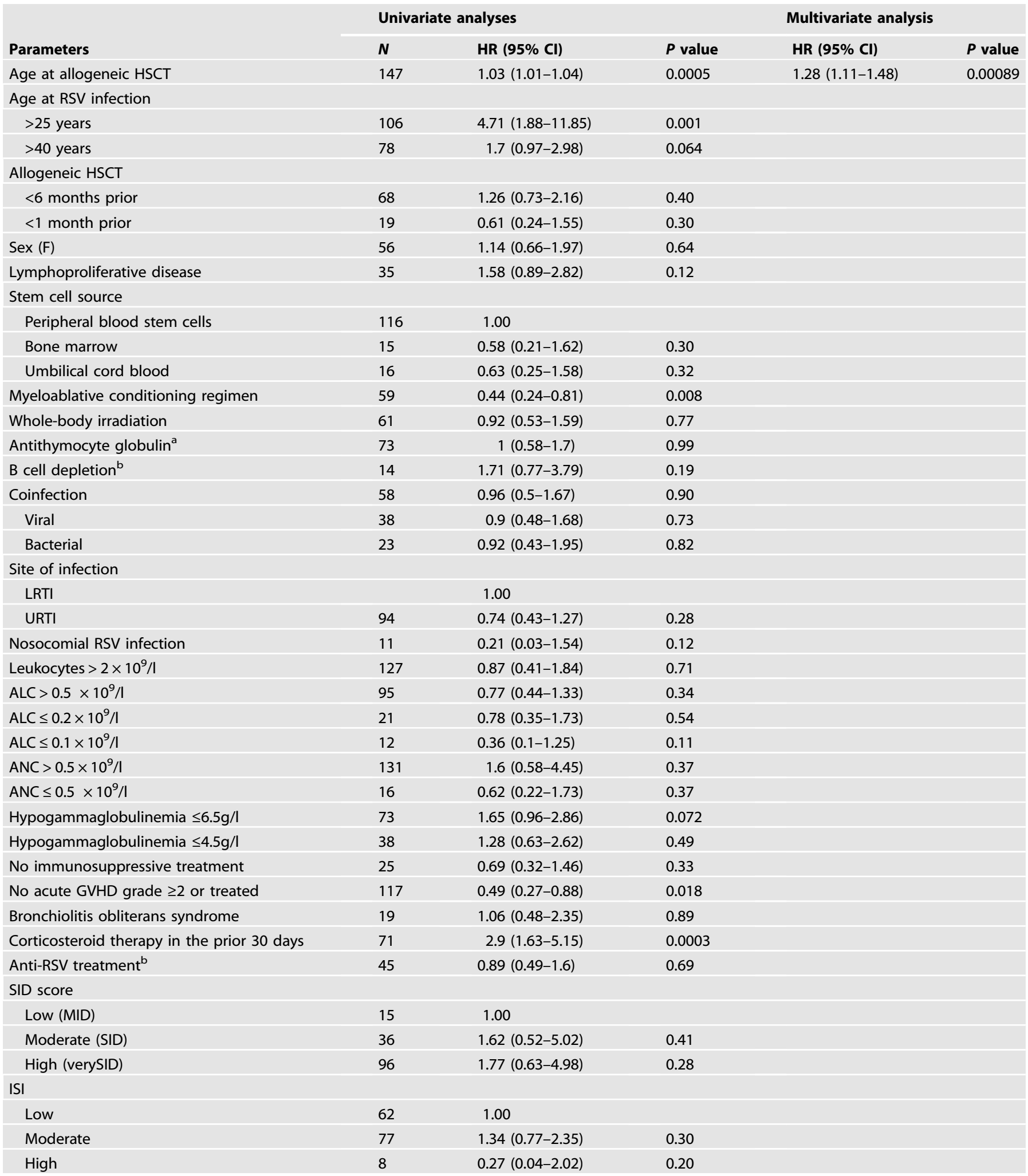

$\mathrm{Cl}$ confidence interval, HSCT haematologic stem cell transplantation, GVHD graft-versus-host disease, RSV respiratory syncytial virus, SID score severe immunodeficiency score, MID moderate immunodeficiency, SID severe immunodeficiency, ISI immunodeficiency scoring index, ALC absolute lymphocyte count, ANC absolute neutrophil count, URTI upper respiratory tract infection, LRTI lower respiratory tract infection.

at the time of conditionning.

${ }^{\mathrm{b}}$ All patient received rituximab (10 patients within the three months prior to RSV infection and four patients between four months and six months prior to RSV infection). 

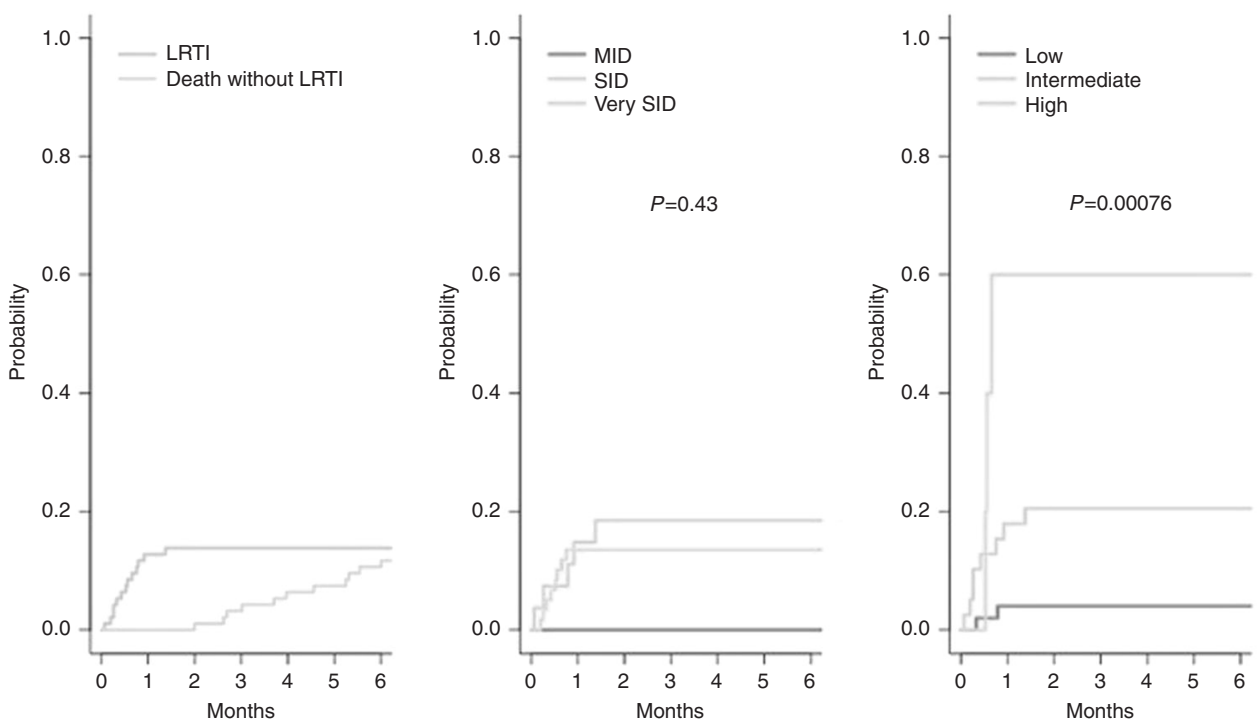

Fig. 3 Cumulative incidence of LRTI in patients with initial URTI. Overall (left plot) or according to the SID score (middle plot) or the ISI (right plot).

patients diagnosed with RSV infection between 1996 and 2009 and 2002 and 2007, respectively. The diagnosis of RSV infection was based exclusively on viral culture or direct immunofluorescence antibody testing (DIFT) in the ISI cohort, whereas only RSVPCR, which is actually used in clinical practice, was used for diagnosis in our cohort. More than $90 \%$ of the patients from the SID score cohort underwent RSV-PCR, but the study included only 34 patients, with $27 \mathrm{HSCT}$ recipients [11]. PCR, used in the most recent studies, is much more sensitive than viral culture or DIFT for the identification of any community-acquired respiratory virus (CARV) and allows the detection of lower viral loads [11]. Therefore, it enables the diagnosis of milder RSV infections. Furthermore, testing patients before they undergo HSCT during RSV epidemics allows the delay of HSCT if the test is positive, thereby preventing severe RSV infection occurring early post-HSCT [35]. Thus, more recent studies include a higher proportion of URTI cases than older studies, including more RSV-LRTI cases, with higher mortality rates [36, 37].

We included only allogeneic HSCT patients, including both children and adults, in contrast to the SID score cohort, which considered only adults treated with both autologous and allogeneic HSCT. The prognosis of RSV infection in autologous HSCT patients compared to allogeneic HSCT patients is discordant in the literature [14]; some studies found no difference [15, 21, 31], while others showed increased severity in allogeneic HSCT patients $[38,39]$. Data in paediatric allogeneic HSCT patients are limited. However, while children most often receive myeloablative conditioning, the RSV-attributable mortality rate seems to be lower in children than in adults $(<5 \%)$ [40].

The characteristics of our patients also differed somewhat from those in the ISI cohort. First, the median time from HSCT to RSV infection was longer in our study (196 days) than in the ISI study (155 days). Second, our patients were younger (40.2 vs 47 years). Finally, we included patients with LRTI, whereas the ISI cohort focused on patients with URTI.

Other studies have assessed these scores in cohorts of allogeneic HSCT recipients infected with various CARVs, including variable proportions of patients infected with RSV [8]. The results regarding the validation of these scores are discordant among the different studies regarding both mortality and progression to LRTI $[9,12,30-32,37,41,42]$. Only one study focused on 45 RSV infections in adult allogeneic HCT recipients exclusively diagnosed by PCR [42]. The authors could validate the ISI for mortality but not for LRTI progression [42].

We found that only advanced age was an independent risk factor for overall and 90-day mortality in our entire cohort. Age was taken into consideration only in the ISI and not in the SID score [11, 16]. We identified other risk factors for mortality in univariable analyses that are consistent with the variables included in either the ISI or SID score, i.e. GVHD and corticosteroid therapy. We also found that hypogammaglobulinemia $\leq 6.5 \mathrm{~g} / \mathrm{l}$ was associated with 90-day mortality, whereas this variable is only part of the SID score and not the ISI. Surprisingly, we did not identify low lymphocyte or neutrophil counts as prognostic factors for either overall or 90-day mortality, whereas they were associated with progression to LRTI. Similarly, we did not find any difference in prognostic impact between URTI and LRTI. The lack of a difference in mortality between LRTI and URTI can be explained by our low rate of presumptive LRTI among all LRTI cases $(5.7 \%$ vs $58.3 \%$ in the SID score cohort). Waghmare et al. showed that possible LRTI can be misleading and that the prognosis was worse in presumptive LRTI [43]. In contrast to other studies, we found that myeloablative conditioning was associated with better survival. Our discordant result could be attributable to the widespread use of nonmyeloablative conditioning regimens in adults, representing $60 \%$ of our entire cohort and $73 \%$ of our adult population. Only $58 \%$ of patients in the ISI cohort and $33 \%$ in the SID score cohort underwent nonmyeloablative conditioning. Notably, $46 \%$ of our patients who underwent myeloablative conditioning were less than 18 years old, and no deaths were observed in this young population.

Multivariate analysis confirmed that both moderate- and highrisk patients according to the ISI were at risk for progression to LRTI. The prediction of LRTI progression was not significant for the SID score, although no patients progressed to LRTI in the lowerrisk group.

Because RSV infections in pediatric allogeneic HCT recipients may differ from those occurring in adult HCT recipients, we reran the analyses by removing the 29 children from our cohort. Of note, the ISI cohort included children but not the SID score cohort. Results did not change regarding both predictions for mortality and LRTI. However, a low leukocytes count was identified as another factor associated with mortality.

Based on a recent, large multicentric retrospective cohort of allogeneic HSCT recipients with PCR-confirmed RSV infection, we 
Table 4. Univariate and multivariate analyses for progression to lower respiratory tract infection in patients with upper respiratory tract infection.

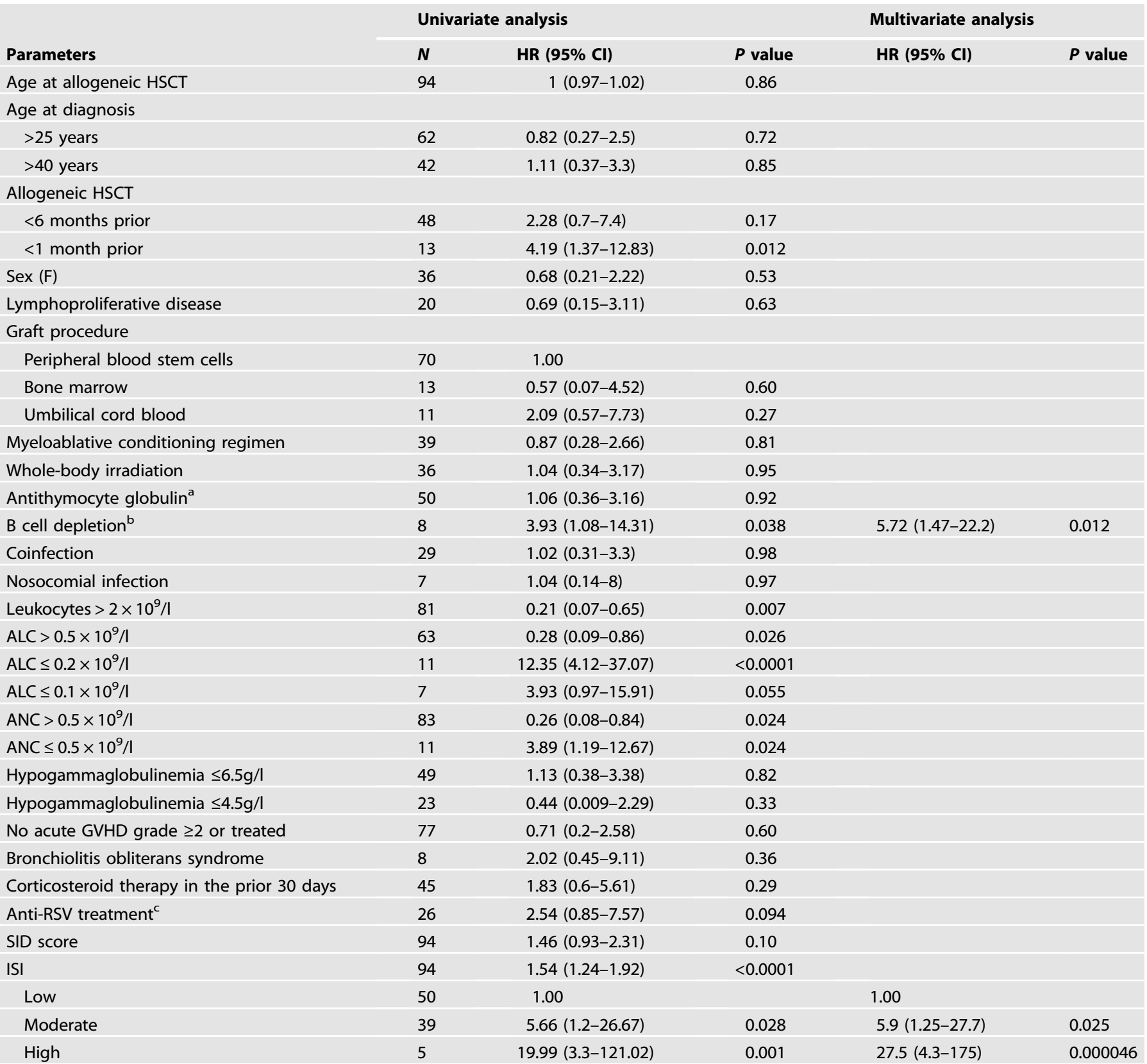

Cl confidence interval, HSCT haematologic stem cell transplantation, GVHD graft-versus-host disease, RSV respiratory syncytial virus, SID score severe immunodeficiency score, ISI immunodeficiency scoring index, ALC absolute lymphocyte count, ANC absolute neutrophil count.

a at the time of conditioning.

${ }^{\mathrm{b}}$ All patients received rituximab (within the three months prior to RSV infection for $\mathrm{x}$ patients and between four months and six months prior to RSV infection for y patients).

${ }^{\mathrm{C}}$ Ribavirine and/or intravenous polyclonal immunoglobulins.

confirmed a reduction in morbidity and mortality compared with historical cohorts. This result could explain why we could not fully validate either the ISI or the SID score, specifically regarding the prediction of mortality. However, we confirmed that immunosuppressive factors were determinants for both progression from URTI to LRTI and mortality. The impact of RSV treatment was not found to be a significant prognostic factor, but our study was not appropriately designed to assess this outcome. Our study provides recent information on cases of RSV infection diagnosed by PCR and should help to better design future trials.

\section{REFERENCES}

1. Legrand M, Max A, Peigne V, Mariotte E, Canet E, Debrumetz A, et al. Survival in neutropenic patients with severe sepsis or septic shock*. Crit Care Med. 2012;40:43-9.

2. Griffiths C, Drews SJ, Marchant DJ. Respiratory syncytial virus: infection, detection, and new options for prevention and treatment. Clin Microbiol Rev. 2017;30:277-319.

3. Ljungman P, Gleaves CA, Meyers JD. Respiratory virus infection in immunocompromised patients. Bone Marrow Transpl. 1989;4:35-40.

4. Srinivasan A, Wang C, Srivastava DK, Burnette K, Shenep JL, Leung W, et al. Timeline, epidemiology, and risk factors for bacterial, fungal, and viral infections 
in children and adolescents after allogeneic hematopoietic stem cell transplantation. Biol Blood Marrow Transpl. 2013;19:94-101.

5. Hirsch HH. Virus infections post transplant: risk and immunity. Transpl Infect Dis. 2005;7:97-8.

6. Chemaly RF, Shah DP, Boeckh MJ. Management of respiratory viral infections in hematopoietic cell transplant recipients and patients with hematologic malignancies. Clin Infect Dis. 2014;59:S344-51.

7. Shah DP, Ghantoji SS, Mulanovich VE, Ariza-Heredia EJ, Chemaly RF. Management of respiratory viral infections in hematopoietic cell transplant recipients. Am J Blood Res. 2012;2:203-18.

8. Ison MG, Hirsch HH. Community-acquired respiratory viruses in transplant patients: diversity, impact, unmet clinical needs. Clin Microbiol Rev. 2019;32: e00042-19. https://doi.org/10.1128/CMR.00042-19.

9. Spahr Y, Tschudin-Sutter S, Baettig V, Compagno F, Tamm M, Halter J, et al. Community-acquired respiratory paramyxovirus infection after allogeneic hematopoietic cell transplantation: a single-center experience. Open Forum Infect Dis. 2018;5:ofy077.

10. Martino R, Porras RP, Rabella N, Williams JV, Rámila E, Margall N, et al. Prospective study of the incidence, clinical features, and outcome of symptomatic upper and lower respiratory tract infections by respiratory viruses in adult recipients of hematopoietic stem cell transplants for hematologic malignancies. Biol Blood Marrow Transpl. 2005;11:781-96.

11. Khanna N, Widmer AF, Decker M, Steffen I, Halter J, Heim D, et al. Respiratory syncytial virus infection in patients with hematological diseases: single-center study and review of the literature. Clin Infect Dis. 2008;46:402-12. 1

12. Wang L, Allen J, Diong C, Goh Y-T, Gopalakrishnan S, Ho A, et al. Respiratory virus infection after allogeneic hematopoietic stem cell transplant in a tropical center: Predictive value of the immunodeficiency scoring index. Transpl Infect Dis. 2017;19:e12693.

13. Rowan CM, Gertz SJ, Zinter MS, Moffet J, Bajwa RPS, Barnum JL, et al. A multicenter investigation of respiratory syncytial viral infection in children with hematopoietic cell transplantation. Transpl Infect Dis. 2018;20:e12882.

14. Ljungman P. Respiratory syncytial virus in hematopoietic cell transplant recipients: factors determining progression to lower respiratory tract disease. J Infect Dis. 2014;209:1151-2.

15. Kim Y-J, Guthrie KA, Waghmare A, Walsh EE, Falsey AR, Kuypers J, et al. Respiratory syncytial virus in hematopoietic cell transplant recipients: factors determining progression to lower respiratory tract disease. J Infect Dis. 2014;209:1195-204.

16. Shah DP, Ghantoji SS, Ariza-Heredia EJ, Shah JN, El Taoum KK, Shah PK, et al. Immunodeficiency scoring index to predict poor outcomes in hematopoietic cell transplant recipients with RSV infections. Blood 2014;123:3263-8.

17. Shah DP, Ghantoji SS, Shah JN, El Taoum KK, Jiang Y, Popat U, et al. Impact of aerosolized ribavirin on mortality in 280 allogeneic haematopoietic stem cell transplant recipients with respiratory syncytial virus infections. J Antimicrobial Chemother. 2013;68:1872-80.

18. Update on Community-acquired respiratory viruses in hematology patients Final Slide Set.pdf [Internet]. [cited 2021 Apr 27]. Available from: http://www.ecilleukaemia.com/resources/Update\%20on\%20Community-acquired\% 20respiratory\%20viruses\%20in\%20hematology\%20patients $\% 20-\% 20$ Final\% 20Slide\%20Set.pdf.

19. Shah JN, Chemaly RF. Management of RSV infections in adult recipients of hematopoietic stem cell transplantation. Blood 2011;117:2755-63.

20. Casey J, Morris K, Narayana M, Nakagaki M, Kennedy GA. Oral ribavirin for treatment of respiratory syncitial virus and parainfluenza 3 virus infections post allogeneic haematopoietic stem cell transplantation. Bone Marrow Transpl. 2013;48:1558-61.

21. Lehners N, Schnitzler P, Geis S, Puthenparambil J, Benz MA, Alber B, et al. Risk factors and containment of respiratory syncytial virus outbreak in a hematology and transplant unit. Bone Marrow Transpl. 2013;48:1548-53.

22. Stamouli M, Tsonis I, Gkirkas K, Economopoulou C, Siafakas N, Pournaras S, et al. Oral ribavirin is a highly effective treatment for lower respiratory tract infections due to respiratory syncytial virus or parainfluenza after allogeneic stem cell transplantation. Bone Marrow Transpl. 2021;56:511-3.

23. Boeckh M, Englund J, Li Y, Miller C, Cross A, Fernandez H, et al. Randomized controlled multicenter trial of aerosolized ribavirin for respiratory syncytial virus upper respiratory tract infection in hematopoietic cell transplant recipients. Clin Infect Dis. 2007;44:245-9. 15

24. Chemaly RF, Dadwal SS, Bergeron A, Ljungman P, Kim Y-J, Cheng G-S, et al. A phase 2, randomized, double-blind, placebo-controlled trial of presatovir for the treatment of respiratory syncytial virus upper respiratory tract infection in hematopoietic-cell transplant recipients. Clin Infect Dis. 2020 ;71:2777-86. 31

25. Marty FM, Chemaly RF, Mullane KM, Lee D-G, Hirsch HH, Small CB, et al. A phase $2 \mathrm{~b}$, randomized, double-blind, placebo-controlled multicenter study evaluating antiviral effects, pharmacokinetics, safety, and tolerability of presatovir in hematopoietic cell transplant recipients with respiratory syncytial virus (RSV) infection of the lower respiratory tract. Clin Infect Dis. 2020;71:2787-95. https:// doi.org/10.1093/cid/ciz1167.

26. Jagasia MH, Greinix HT, Arora M, Williams KM, Wolff D, Cowen EW, et al. National institutes of health consensus development project on criteria for clinical trials in chronic graft-versus-host disease: I. the 2014 diagnosis and staging working group report. Biol Blood Marrow Transplant. 2015;21:389-401.e1.

27. Khanna N, Steffen I, Studt J-D, Schreiber A, Lehmann T, Weisser M, et al. Outcome of influenza infections in outpatients after allogeneic hematopoietic stem cell transplantation. Transpl Infect Dis. 2009;11:100-5.

28. Grambsch PM, Therneau TM. Proportional hazards tests and diagnostics based on weighted residuals. Biometrika 1994;81:515-26.

29. Chatzis O, Darbre S, Pasquier J, Meylan P, Manuel O, Aubert JD, et al. Burden of severe RSV disease among immunocompromised children and adults: a 10 year retrospective study. BMC Infect Dis. 2018;18:111.

30. Piñana JL, Pérez A, Montoro J, Hernani R, Lorenzo I, Giménez E, et al. The effect of timing on community acquired respiratory virus infection mortality during the first year after allogeneic hematopoietic stem cell transplantation: a prospective epidemiological survey. Bone Marrow Transpl. 2020;55:431-40.

31. Vakil E, Sheshadri A, Faiz SA, Shah DP, Zhu Y, Li L, et al. Risk factors for mortality after respiratory syncytial virus lower respiratory tract infection in adults with hematologic malignancies. Transpl Infect Dis. 2018;20:e12994.

32. Akhmedov M, Wais V, Sala E, Neagoie A, Nguyen TM, Gantner A, et al. Respiratory syncytial virus and human metapneumovirus after allogeneic hematopoietic stem cell transplantation: Impact of the immunodeficiency scoring index, viral load, and ribavirin treatment on the outcomes. Transpl Infect Dis. 2020;22.

33. Champlin RE, Whimbey E. Community respiratory virus infections in bone marrow transplant recipients: the M.D. Anderson Cancer Center experience. Biol Blood Marrow Transpl. 2001;7:8S-10S.

34. Harrington RD, Hooton TM, Hackman RC, Storch GA, Osborne B, Gleaves CA, et al. An outbreak of respiratory syncytial virus in a bone marrow transplant center. J Infect Dis. 1992;165:987-93.

35. Peck AJ, Corey L, Boeckh M. Pretransplantation respiratory syncytial virus infection: impact of a strategy to delay transplantation. Clin Infect Dis. 2004;39:673-80.

36. Khawaja F, Chemaly RF. Respiratory syncytial virus in hematopoietic cell transplant recipients and patients with hematologic malignancies. Haematologica 2019;104:1322-31.

37. Montoro J, Sanz J, Lorenzo I, Balaguer-Roselló A, Salavert M, Gómez MD, et al. Community acquired respiratory virus infections in adult patients undergoing umbilical cord blood transplantation. Bone Marrow Transplant. 2020;55:2261-9.

38. Ljungman P, Ward KN, Crooks BNA, Parker A, Martino R, Shaw PJ, et al. Respiratory virus infections after stem cell transplantation: a prospective study from the Infectious Diseases Working Party of the European Group for Blood and Marrow Transplantation. Bone Marrow Transpl. 2001;28:479-84.

39. Hassan IA, Chopra R, Swindell R, Mutton KJ. Respiratory viral infections after bone marrow/peripheral stem-cell transplantation: the Christie hospital experience 1. Bone Marrow Transplant. 2003;32:73-7.

40. Fisher BT, Danziger-Isakov L, Sweet LR, Munoz FM, Maron G, Tuomanen E, et al. A multicenter consortium to define the epidemiology and outcomes of inpatient respiratory viral infections in pediatric hematopoietic stem cell transplant recipients. J Pediatr Infect Dis Soc. 2018;7:275-82.

41. Piñana JL, Gómez MD, Pérez A, Madrid S, Balaguer-Roselló A, Giménez E, et al. Community-acquired respiratory virus lower respiratory tract disease in allogeneic stem cell transplantation recipient: Risk factors and mortality from pulmonary virus-bacterial mixed infections. Transpl Infect Dis. 2018;20:e12926.

42. Damlaj M, Bartoo G, Cartin-Ceba R, Gijima D, Alkhateeb HB, Merten J, et al. Corticosteroid use as adjunct therapy for respiratory syncytial virus infection in adult allogeneic stem cell transplant recipients. Transpl Infect Dis. 2016;18:216-26.

43. Waghmare A, Xie H, Kimball L, Yi J, Özkök S, Leisenring W, et al. Supplemental oxygen-free days in hematopoietic cell transplant recipients with respiratory syncytial virus. J Infect Dis. 2017;216:1235-44. 5

\section{ACKNOWLEDGEMENTS}

The authors thank Stéphane Cassonnet for his technical assistance. The authors thank EGMOS, a patient association, for their support.

\section{AUTHOR CONTRIBUTIONS}

$A L H, S C$ and $A B$ conceived the study. $A L H, L B, M S, J L, S C$ and $A B$ designed the work that led to the submission. ALH, LB, MS, JL, RPL, FR, CS, VH, JHD, CR, SF, FG, TC, SC and $A B$ acquired data, and played an important role in interpreting the results. $A L H, S C$ and $A B$ drafted the manuscript. All authors revised the manuscript, approved the final version and agreed to be accountable for all aspects of the work in ensuring that questions related to the accuracy or integrity of any part of the work are appropriately investigated and resolved. 
COMPETING INTERESTS

The authors declare no competing interests.

\section{ADDITIONAL INFORMATION}

Supplementary information The online version contains supplementary material available at https://doi.org/10.1038/s41409-021-01462-z.
Correspondence and requests for materials should be addressed to Anne Bergeron.

Reprints and permission information is available at http://www.nature.com/ reprints

Publisher's note Springer Nature remains neutral with regard to jurisdictional claims in published maps and institutional affiliations. 